\title{
Mechanical behavior of carbon/flax hybrid composites for structural applications
}

\author{
V Fiore', A Valenza' and G Di Bella ${ }^{2}$
}

\begin{abstract}
In this work, the influence of an unidirectional carbon fabric layer on the mechanical performances of bidirectional flax fabric/epoxy composites used for structural applications was studied. Two different bidirectional flax fabrics were used to produce flax fabric reinforced plastic (FFRP) laminates by a vacuum bagging process: one is normally used to make curtains; the other, heavier and more expensive than the previous one, is usually used as reinforcement in composite structures. In order to realize hybrid structures starting from FFRP, an unidirectional UHM carbon fabric was used to replace a bidirectional flax fabric. Tensile and three-point bending tests were performed to evaluate the mechanical properties of the laminates investigated (both FFRP and hybrids). Furthermore, the mechanical behavior of the different bidirectional flax fabrics was analyzed by carrying out tensile tests. The experimental tests showed that the structures reinforced with flax fabrics, normally used to make curtains, present better flexural properties than that of others while, in tensile configuration, these last show higher modulus and strength. Moreover, both FFRP laminates show low mechanical properties, which do not allow their use in structural applications while the presence of one external layer of unidirectional carbon involves remarkable increase in their properties. According to this study, the hybrid composites realized could be used in several structural applications (i.e., nautical and automotive).
\end{abstract}

\section{Keywords}

Hybrid composite, natural fiber, mechanical properties, vacuum bagging

\section{Introduction}

Fabric reinforced plastic (FRP) materials are widely used in several key applications such as ships, aircraft, buildings, bridges, automobiles, and other transportation vehicles because of their good properties (i.e., high mechanical strength and stiffness, high impact resistance, low weight, corrosion resistance, and low maintenance cost).

In the last few years the use of natural fibers as reinforcement of composite materials, as an alternative to the synthetics (e.g., glass, carbon, or kevlar fibers), has received growing attention, owing to the following reasons: their specific properties, price, advantages for health, and recyclability.

Nevertheless, natural fibers also possess some of the following negative characteristics that do not allow their use as the only reinforcement of composite materials in several structural applications: high hydrophilic behavior, low mechanical properties, and poor adhesion with polymeric matrix. Moreover the mechanical, physical, and chemical properties of these vegetable fibers are strongly harvest dependent, influenced by climate, location, soil characteristics, and weather circumstances.

There are a wide variety of different natural fibers, which can be applied as reinforcements of composite materials. Flax, hemp, jute, kenaf, and sisal are the most widely used because of their properties and availability.

Particularly, flax fibers (Linum usitatissimum) have attracted the attention of many researchers in the composites industry due to their better properties, when compared to other natural fibers. Particularly, the tensile strength and Young's modulus of flax ultimate

\footnotetext{
'Department of "Ingegneria Civile, Ambientale e Aerospaziale", University of Palermo, Palermo, Italy

${ }^{2}$ CNR ITAE, Via Salita Santa Lucia sopra Contesse 5, Messina, Italy

Corresponding author:

$\checkmark$ Fiore, Department of "Ingegneria Civile, Ambientale e Aerospaziale", University of Palermo, 90128 Palermo, Italy

Email: vincenzo.fiore@unipa.it; antonino.valenza@unipa.it
} 
fibers are equal to about $1340 \mathrm{MPa}$ and $54 \mathrm{GPa}$, respectively. With a density of around $1400 \mathrm{~kg} / \mathrm{m}^{3}$, the specific properties of these fibers are comparable with those of E-glass fibers, which have a tensile strength of $2000 \mathrm{MPa}$, a Young's modulus of $76 \mathrm{GPa}$, and a density of around $2560 \mathrm{~kg} / \mathrm{m}^{3}$.

The use of this type of natural fiber dates back to the beginning of last century: in 1941, flax and hemp fibers were used in resin matrix composites for the bodywork of a Henry Ford car, which claimed to have an 'impact strength 10 times greater than steel. ${ }^{2}$

Nowadays, flax is the most widely used natural fiber in the European automotive industry, representing $71 \%$ of the natural fibers consumed in the year 2000 . Most of this is short-fiber flax obtained as a by-product of the textile industry. ${ }^{3}$ As other natural fibers, flax is typically combined with polypropylene, polyester, or polyurethane to produce components like door and trunk liners, parcel shelves, seat backs, interior sunroof shields, and headrests. ${ }^{4}$

Several research works analyzed the behavior of composite structures reinforced with flax fibers. Musialak et $\mathrm{al}^{5}$ improved the behavior of the flax fibers by reducing percentage of pectin. Assarar et al. ${ }^{6}$ studied the effects of water aging on the tensile characteristics, water absorption, and acoustic emission of flax-fiber composites, compared with glass-fiber composites. Lamy and Baley ${ }^{7}$ developed a model, validated by an experimental analysis on flax/epoxy laminates, to predict the stiffness of the flax fibers by varying their diameter. Xiao-Yun et al. ${ }^{8}$ realized and tested composite boards with flax fibers as the reinforcement material and polyactic acid fiber as the matrix. Flax fibers were also used by Charlet et al. ${ }^{9}$ to produce unidirectional composites by two different methods: hand impregnation and compression molding.

In a previous work of the authors ${ }^{10}$ several bidirectional flax fabrics, usually used to make curtains, were employed as reinforcement of an epoxy matrix. Four different laminates were made by a vacuum bagging process, varying both the areal weight and the treatment of the fabrics. The experimental results showed that both the parameters investigated (areal weight and treatment) are greatly significant for the flexural properties of the laminates while in tensile configuration, the areal weight has a significant effect only on the modulus.

Definitely the laminate constituted by six layers of bidirectional flax fabric, chemically treated (i.e., withening and couloring) and with areal weight equal to $150 \mathrm{~g} / \mathrm{m}^{2}$ showed the best mechanical performance both in flexural (average values of failure stress and Young's modulus equal to $76.4 \mathrm{MPa}$ and $7.41 \mathrm{GPa}$, respectively) and in tensile properties (average values of failure stress and Young's modulus equal to 78.6 $\mathrm{MPa}$ and $1.79 \mathrm{GPa}$, respectively).
Aim of the present work is to compare the mechanical properties of this last laminate with that of a new one, reinforced with a different kind of bidirectional flax fabric, used not to make curtains but rather as reinforcement in composite materials.

Another aim of the authors is to increase the mechanical properties of these FFRP laminates, making these structures suitable for structural applications (e.g., in nautical or automotive field). Owing to this, hybrid composites were produced starting from FFRP laminates and a layer of bidirectional flax fabric was replaced with unidirectional carbon nonwoven fabric.

Hybrid composites are commonly used when a combination of properties of different types of fibers needs to be achieved, or when longitudinal performances as well as lateral mechanical ones are required. In literature there are many works related to these composites $^{11-16}$ but very few regarding hybrid composite reinforced by natural fibers and carbon types. ${ }^{17}$ One of the most recent applications of the latter is regarding the realization of an ecologic prototype boat named 'Araldite,' which represents the smallest offshore racing boat (hull length $=6.5 \mathrm{~m}$, hull width $=3 \mathrm{~m}$, weight $=750 \mathrm{~kg}$, sail surface $=120 \mathrm{~m}^{2}$ ), which can sail the Atlantic sea. This carbon/flax prototype was constructed at the IDB Marine de Tregnunc Shipyard in Britanny (FR) by reaching an amount of flax fibers up to $50 \%(75-80 \%$ for hull and deck) of the total reinforcement weight. ${ }^{18}$

\section{Experimental setup}

\section{Materials and manufacturing}

All the laminates investigated were realized with a single lamination using the vacuum bagging technique, cured at room temperature for $24 \mathrm{~h}$ and then post-cured at $60^{\circ} \mathrm{C}$ for $8 \mathrm{~h}$.

Two different bidirectional flax fabrics (Figure 1) were used to produce FFRP laminates. The first one (in the next 'BD220') is a balanced twill weave fabric, having areal weight of $220 \mathrm{~g} / \mathrm{m}^{2}$ and cost per unit of area of $11.65 € / \mathrm{m}^{2}$. This is normally used as reinforcement in composite structures.

The second one (in the next 'BD150') is an unbalanced plain weave fabric with areal weight equal to $150 \mathrm{~g} / \mathrm{m}^{2}$ and cost per unit of area of $6 € / \mathrm{m}^{2}$. This kind of flax fabric is treated through chemical treatments of withening and couloring and normally used to make curtains.

The hybrid structures were produced replacing in each FFRP laminate a layer of bidirectional flax fabric with one of unidirectional UHM carbon nonwoven fabric with areal weight of $320 \mathrm{~g} / \mathrm{m}^{2}$ (in the next ' $\mathrm{C} / \mathrm{UD} 320$ '). 


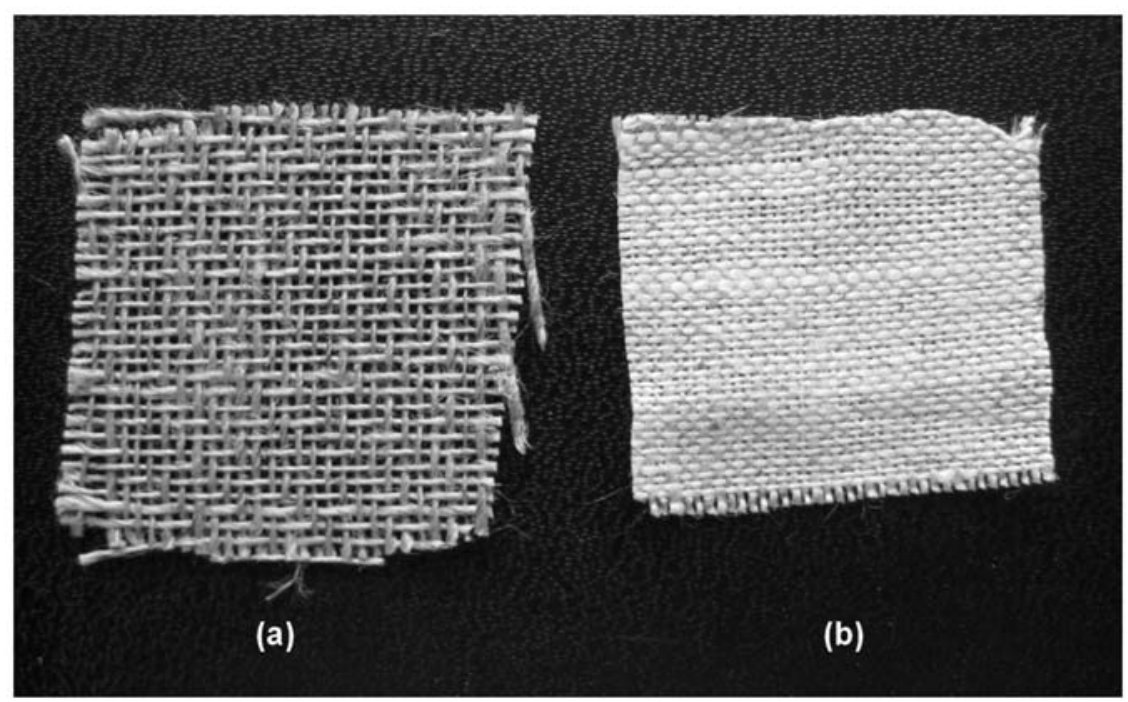

Figure I. Wave architectures of (a) BD220 and (b) BDI50 woven fabrics.

The stacking sequence of the laminates (both FFRP and hybrids) is shown in Table 1: each structure is constituted by six fabric layers in a matrix of epoxy resin (Sicomin SR 8500). It is to be noted that the F150 structure is the one, which showed good mechanical properties among the FFRP structures investigated in the paper of the authors Di Bella et al. ${ }^{10}$ cited in the introduction section. In each hybrid structure, one external layer of bidirectional flax fabric is replaced with one layer of unidirectional carbon fabric.

\section{Mechanical testing}

The mechanical tests were performed on laminate structures by using a Zwick-Roell Universal Testing Machine (UTM), equipped with a load cell of $600 \mathrm{kN}$, according to ASTM standards. ${ }^{19,20}$ Five samples for each structure were tested at room temperature both for three-point bending configuration and for tensile one.

Regarding the flax fabrics, the tensile characterization was carried out by using an Instron UTM equipped with a load cell of $1 \mathrm{kN}$, according to ASTM standard. ${ }^{21}$

\section{Results and discussion}

\section{Flexural characterization}

Table 2 shows flexural properties of the structures investigated. Regarding the FFRP laminates, it is possible to observe that the flexural properties of the F220 structure decrease when compared to those of F150. Particularly, the F220 structure shows decreases of
Table I. Investigated structures

\begin{tabular}{lllll}
\hline \multirow{5}{*}{ Layer } & \multicolumn{4}{l}{ Laminate } \\
\cline { 2 - 5 } & FI50 & F220 & FI50/C & F220/C \\
\hline BDI50 & BD220 & BDI50 & BD220 \\
2 & BDI50 & BD220 & BDI50 & BD220 \\
3 & BDI50 & BD220 & BDI50 & BD220 \\
4 & BDI50 & BD220 & BDI50 & BD220 \\
5 & BDI50 & BD220 & BDI50 & BD220 \\
6 & BDI50 & BD220 & C/UD320 & C/UD320 \\
Thickness $(\mathrm{mm})$ & $I .57 \pm 0.03$ & $2.15 \pm 0.02$ & $2.47 \pm 0.07$ & $3.17 \pm 0.04$ \\
$P_{f}(\%)$ & $54.0 \pm 0.5$ & $45.6 \pm 0.5$ & $51.5 \pm 3.3$ & $49.4 \pm 1.2$ \\
\hline
\end{tabular}

Table 2. Flexural properties of the laminates

\begin{tabular}{lll}
\hline & $E(\mathrm{GPa})$ & $\sigma(\mathrm{MPa})$ \\
\hline FI50 & $7.41 \pm 0.39$ & $76.42 \pm 3.59$ \\
F220 & $5.35 \pm 0.21$ & $61.05 \pm 2.28$ \\
$\mathrm{FI50/C}$ & $23.84 \pm 0.74$ & $160.42 \pm 10.46$ \\
F220/C & $14.41 \pm 1.38$ & $85.00 \pm 5.38$ \\
\hline
\end{tabular}

about $38.5 \%$ and $25.2 \%$ in the flexural modulus and strength, respectively.

These results can be explained considering the different wave architecture of the flax fabrics used in the structures investigated. Particularly, as shown in Figure 1, the BD220 fabric is a balanced twill weave fabric and presents the same number of yarns in both warp and weft directions. On the other side, the BD150 fabric is an unbalanced plain weave fabric characterized by a tighter weave architecture than the previous one 
(i.e., shows less gaps between the fibers in the weft and warp directions).

Such different wave architectures allow the BD220 fabric to absorb more resin than the fabric used for curtains since the resin, driven by vacuum pressure during the productions process, fills better the gaps of the BD220 fabric.

These considerations can explain the higher matrix content $(54.4 \%$ vs $46.0 \%)$, greater thickness $(2.15 \mathrm{~mm}$ vs $1.57 \mathrm{~mm}$ ) and, consequently, bad flexural properties of the F220 structure, when compared to F150.

Regarding the failure modes of the FFRP laminates, unlike the F150 structure, the F220 shows a catastrophic yielding due to the premature degradation phenomena of the matrix (e.g., matrix cracking), followed by the delamination at the interface between two adjacent layers.

The degradation phenomena of the matrix, though not visible, frequently affects composite structures characterized by a resin excess, i.e., F220 in present work. This is due to the brittle nature of the thermosetting resins (e.g., epoxy), which can undergo only a limited deformation prior to fracture: $:^{22}$ they show poor resistance to crack propagation and low impact strength, therefore they exhibit low toughness. ${ }^{23}$

The catastrophic yielding is confirmed by the sudden stress drop of the stress-strain curve of the F220 structure (Figure 2). In the hybrid structures, the replacement of one layer of bidirectional flax fabric with one of unidirectional carbon leads to an increase in the flexural properties for each structure investigated.

The F150/C hybrid structure shows improvements of about $221.7 \%$ and $110 \%$ in the flexural modulus and strength compared to those of the reference FFRP structure (i.e., F150), respectively. On the other hand, the hybrid structure reinforced with the BD220 fabric (i.e., F220/C) shows an elastic modulus and tensile strength in excess of $169.3 \%$ and $39.2 \%$ compared to those of the reference structure, respectively.

From these data it is possibile to note that the beneficial effect of the carbon layer is higher for the structure that, as discussed above, already appear as the best among those references (i.e., F150).

Considering the constituents content, the great difference measured among between the FFRP structures decreases due to the presence of unidirectional carbon layer in the hybrid structures: the F150/C structure is characterized by a slighty higher fiber content $(51.5 \%)$ than that of the F220/C (49.4\%).

This is because in both FFRP structures two different flax fabric that, as discussed above, absorb a variable amount of resin according to different wave architecture, are replaced with an identical carbon layer that, vice versa, absorbs an equal resin amount.

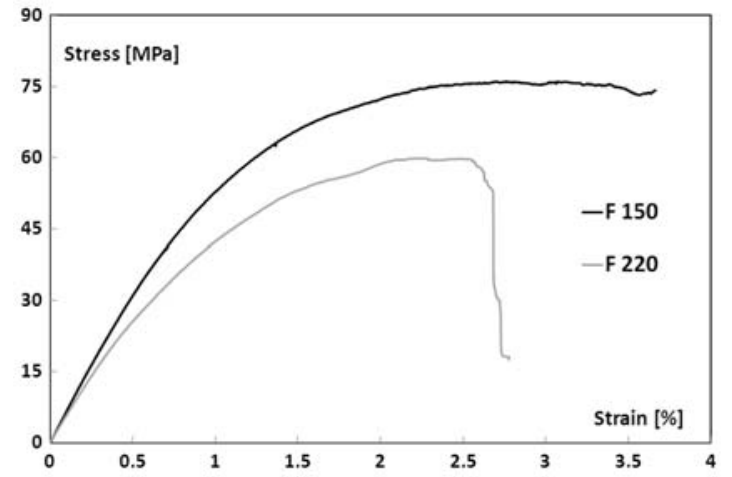

Figure 2. Stress-strain curves of the FFRP laminates (flexural test).

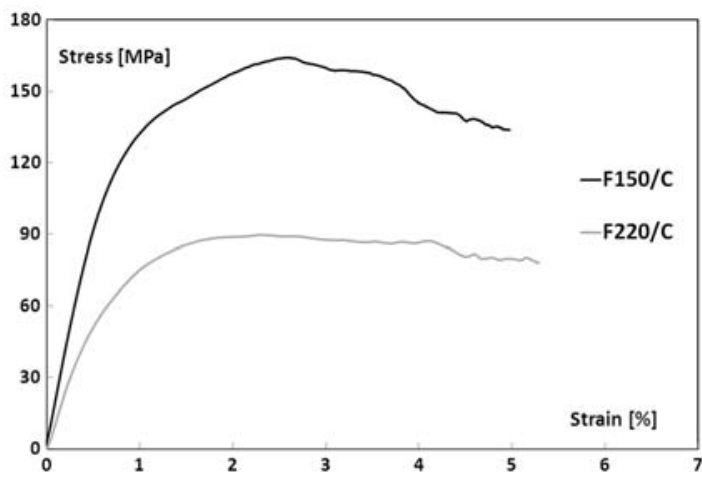

Figure 3. Stress-strain curves of the hybrid laminates (flexural test).

Table 3. Tensile properties of the laminates

\begin{tabular}{lll}
\hline & $E(\mathrm{GPa})$ & $\sigma(\mathrm{MPa})$ \\
\hline $\mathrm{FI} 50$ & $1.79 \pm 0.04$ & $78.63 \pm 1.4 \mathrm{I}$ \\
$\mathrm{F} 220$ & $4.5 \pm 0.15$ & $90.43 \pm 1.47$ \\
$\mathrm{FI50/C}$ & $6.48 \pm 0.32$ & $288.03 \pm 30.23$ \\
$\mathrm{~F} 220 / \mathrm{C}$ & $5.09 \pm 0.34$ & $172.4 \pm 25.5$ \\
\hline
\end{tabular}

Consequently to the similar values of fiber content showed by the hybrid structures, no delamination failure modes occur, as showed by the absence of any catastrophic stress drop in the stress-strain curves (Figure 3).

\section{Tensile characterization}

Table 3 shows tensile properties of the structures investigated. Considering the FFRP laminates, it is possible to observe that that the structures investigated show a different behavior when compared to the previous ones: the structure reinforced with the BD220 fabric shows better tensile properties than those of the structure with 
the fabric used to make curtains. Particularly, the tensile modulus and strength of F220 structure are 151.4\% and $15.0 \%$ when compared to F150, respectively.

Despite the higher fiber content of the F150 structure, its tensile properties (especially the modulus) are lower than those of F220. This could be explained admitting that, for this configuration load, the mechanical performance of the laminates are more influenced by the mechanical properties of the flax fabrics used than by the constituents content of the laminates.

The mechanical properties of the bidirectional flax fabrics were analyzed by carrying out preliminary tensile tests along both the warp and the weft (or cross) direction of each fabric, according to ASTM standard. ${ }^{21}$

As expected from its unbalanced wave architecture, the BD150 fabric showed different tensile behavior when tested in weft or warp direction (Figure 4). This could be attributed to the difference of yarn density in both directions: in the weft direction there is 1.5 times more yarns than in the warp direction.

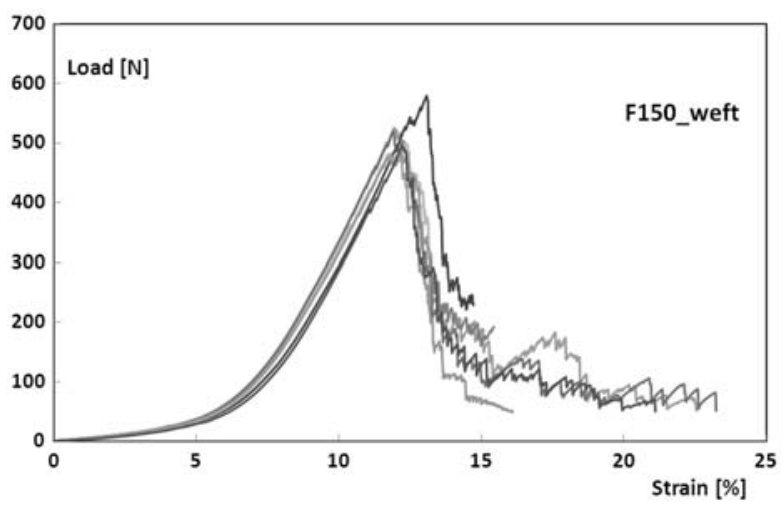

Figure 4. Tensile curves of the BDI50 fabric.
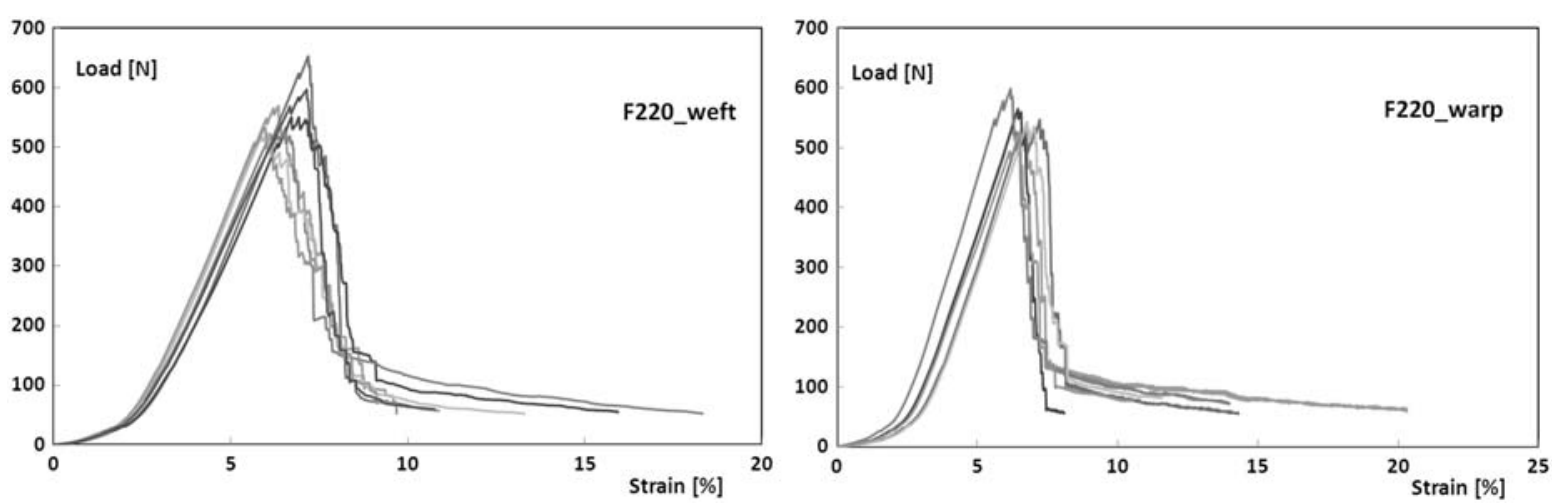

Conversely, since the BD220 fabric shows the same yarn density in the warp and weft directions (i.e., balanced twill wave fabric), it shows similar tensile behavior along both directions (Figure 5).

By comparing the mechanical performances of the bidirectional flax fabrics along the weft direction, it has been found that the breaking force of the BD220 fabric $(580.40 \pm 46.73 \mathrm{~N})$ is greater than that of BD150 $(499.90 \pm 12.74 \mathrm{~N})$ while this last fabric shows an elongation at break about two times greater $(12.20 \pm 0.17 \%$ vs $6.67 \pm 0.52 \%$ ).

These dissimilar tensile properties shown by the flax fabrics are strictly connected to their wave architectures. Like other natural fibers, flax exhibits natural defects, but many of these are also induced through the spinning of the flax yarn and their weaving process. ${ }^{24}$ By comparing the wave architectures of the fabrics, the BD220 twill fabric has fewer interlacing and defects of the yarns than the BD150 plain fabric and, consequently, higher tensile performances.

Keeping into account that, in tensile configuration load, FFRP laminates are loaded along the weft

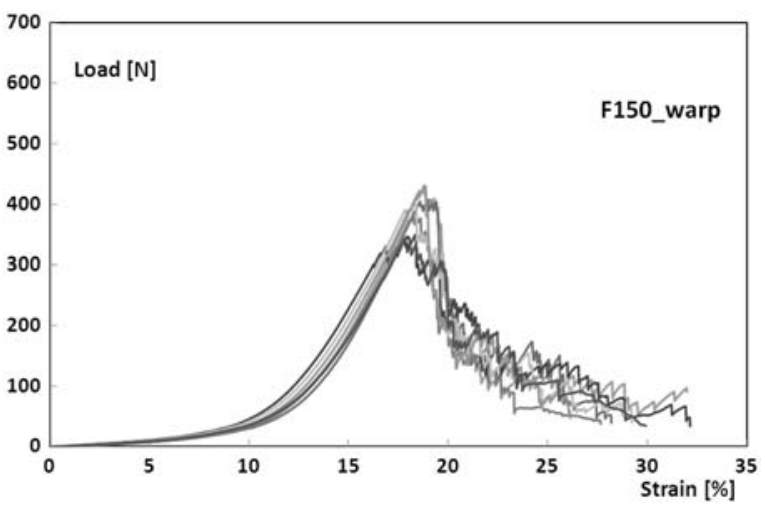

Figure 5. Tensile curves of the BD220 fabric. 
direction of the fabrics, it is consistent that the different tensile performance of the flax fabrics strongly influence the mechanical behavior of the composite structures.

Indeed, as discussed above, the FFRP laminates show very dissimilar values of tensile modulus and comparable values of tensile strength, just like the flax fabrics used as reinforcement.

As in the case of flexural loading, the replacement of one layer of bidirectional flax fabric with one of unidirectional carbon increases significantly the tensile properties of the structures investigated.

The F150/C hybrid structure shows improvements of about $262.0 \%$ and $266.4 \%$ in the tensile modulus and strength compared to those of the reference FFRP structure (i.e., F150), respectively. On the other hand, the F220/C hybrid structure shows an elastic

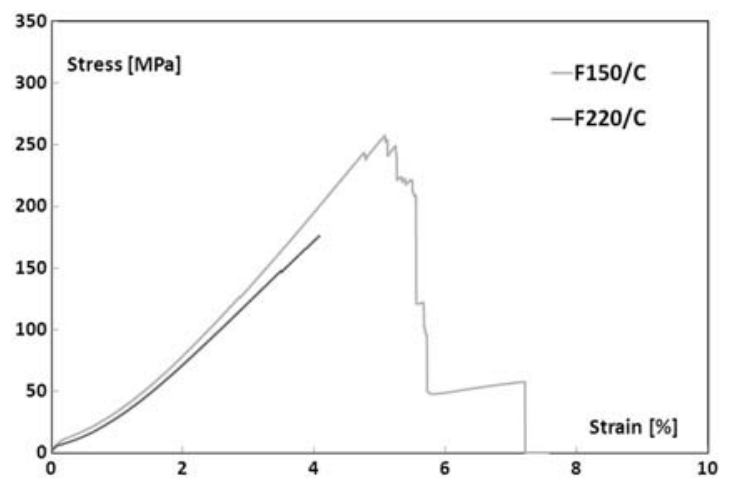

Figure 6. Stress-strain curves of the hybrid laminates (tensile test). modulus and tensile strength in excess of $13.1 \%$ and $90.7 \%$ compared to those of the reference structure, respectively.

As in the flexural characterization, it is possibile to note that the beneficial effect of the carbon layer is higher for the structure reinforced with the flax fabric normally used to make curtains (i.e., the FFRP structures with higher fiber content).

In this case the presence of the carbon layer 'overturns' the tensile performances of the laminates investigated: while the F150 structure, with higher fiber content, has lower tensile properties than F220 (due to the mechanical properties of the fabric used), the carbon layer allows to $\mathrm{F} 150 / \mathrm{C}$ hybrid structure to reach better tensile properties than those of F220/C.

The tensile curve stress-strain for hybrid structures are shown in Figure 6 and it is evident that these laminates exhibit different failure modes. Particularly the F220/C structures fail for tensile failure of the fibers as shown in Figure 7. The flax layers and the carbon one fail at the same time and delamination failure does not occur. This phenomenon prevails on the delamination failure that does not occur.

On the other hand, for the $\mathrm{F} 150 / \mathrm{C}$ structure, the predominant failure mode is the tensile failure of the carbon layer, followed by the delamination at the interface between the carbon layer and the flax one adjacent. Then there is decrease in stress with the crack growth and increase in the delamination area until the tensile failure of the flax layers occurs. Figure 8 shows the F150/C sample with damaged carbon layer, the delamination area, and the failure of the flax layers.

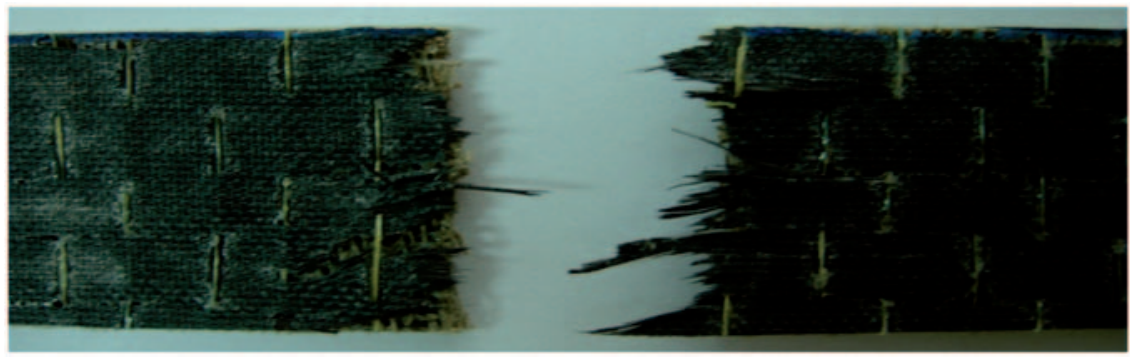

Figure 7. Failure mechanism of the F220/C laminate (tensile test).

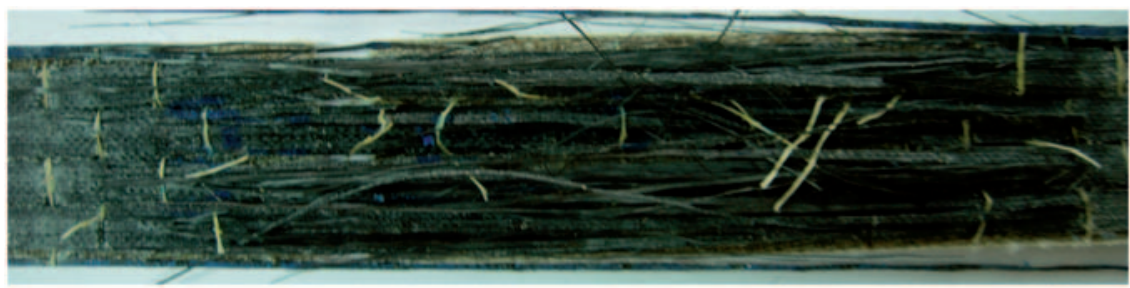

Figure 8. Failure mechanism of the FI50/C laminate (tensile test). 


\section{Conclusions}

The objectives of this work was to compare the mechanical properties of two FFRP laminates and to evaluate the influence on the same properties of an unidirectional carbon fabric layer.

Two different bidirectional flax fabrics were used to produce FFRP laminates by vacuum bagging process: one is normally used to make curtains; the other, heavier and more expensive than the previous one, is usually used as reinforcement in composite structures. In order to realize hybrid structures, an unidirectional UHM carbon fabric was used to replace the external layer of bidirectional flax fabric in each FFRP laminate.

Tensile and three-point bending tests were performed to evaluate the mechanical properties of the laminates investigated (both FFRP and hybrids).

The flexural tests show that the structures reinforced with flax fabrics, normally used to make curtains (i.e., F150) presents better properties in comparison with others (i.e., F220). Conversely, in tensile configuration, both the modulus and strength of the F220 structure is higher than those of F150.

Nevertheless it is noted that both FFRP structures present low mechanical properties, which do not allow their use in structural applications.

Regarding the hybrid structures, the presence of one external layer of unidirectional greatly increases the mechanical properties of the laminates:

- In flexural, the $\mathrm{F} 150 / \mathrm{C}$ hybrid structure shows improvements of about $221.7 \%$ and $110 \%$ in the modulus and strength compared to those of the reference FFRP structures (i.e., F150) while the F220/C shows an elastic modulus and tensile strength in excess of $169.3 \%$ and $39.2 \%$ compared to those of the reference structure (i.e., F220), respectively.

- In tensile, the $\mathrm{F} 150 / \mathrm{C}$ hybrid structure shows improvements of about $262.0 \%$ and $266.4 \%$ in the modulus and strength compared to those of the reference FFRP structure while the F220/C hybrid structure shows an elastic modulus and tensile strength in excess of $13.1 \%$ and $90.7 \%$ compared to those of the reference structure, respectively.

- Definitely the F150/C hybrid structure shows the best mechanical performances both in flexural (average values of failure stress and Young's modulus equal to $160.4 \mathrm{MPa}$ and $23.8 \mathrm{GPa}$, respectively) and in tensile properties (average values of failure stress and Young's modulus equal to $288.0 \mathrm{MPa}$ and $6.5 \mathrm{GPa}$, respectively). These values are comparable with that of other conventional composite laminates normally used in engineering applications.

In conclusion, these results highlight that the carbon/flax hybrid composites realized in this work, could be used in structural applications (e.g., nautical and automotive).

\section{Funding}

This research received no specific grant from any funding agency in the public, commercial, or not-for-profit sectors.

\section{Conflict of interests}

None declared.

\section{References}

1. Liu Q and Hughes M. The fracture behaviour and toughness of woven flax fiber reinforced epoxy composites. Composites Part A 2008; 39(10): 1644-1652.

2. Summerscales J, Dissanayake NPJ, Virk AS and Hall W. A review of bast fibres and their composites. Part 1 Fibres as reinforcement. Composites Part A 2010; 41(10): 1329-1335.

3. Plackett $\mathrm{D}$. The natural fibre-polymer composite industry in Europe-technology and markets. In: Progress on Woodfibre-Plastic Composites Conference, Toronto, 2002.

4. Suddell BC and Evans WJ. The increasing use and application of natural fibre composite materials within the automotive industry. In: 7th International Conference on Woodfibre-Plastic Composites, Madison, 2003.

5. Musialak M, Wrobel-Kwiatkowska M, Kulma A, Starzycka E and Szopa J. Improving retting of fiber through genetic modification of flax to express pectinases. Trans Res 2008; 17(1): 133-147.

6. Assarar M, Scida D, El Mahi A, Poilâne C and Ayad R. Influence of water ageing on mechanical properties and damage events of two reinforced composite materials: flax-fibres and glass-fibres. Mater Design 2011; 32(2): 788-795.

7. Lamy B and Baley C. Stiffness prediction of flax fibersepoxy composite materials. J Mater Sci Lett 2000; 19(11): 979-980.

8. Xiao-Yun W, Qiu-Hong W and Gu H. Research on mechanical behavior of the flax/polyactic acid composites. J Reinf Plast Compos 2010; 29(17): 2561-2567.

9. Charlet K, Jernot JP, Gomina M, Bizet L and Bréard J. Mechanical properties of flax fibers and of the derived unidirectional composites. J Compos Mater 2010; 44(24): 2887-2896.

10. Di Bella G, Fiore V and Valenza A. Effect of areal weight and chemical treatment on the mechanical properties of bidirectional flax fabrics reinforced composites. Mater Des 2010; 31(9): 4098-4103.

11. Abu Talib AR, Ali A, Badie MA, Azida Che Lah N and Golestaneh AF. Developing a hybrid, carbon/glass fiberreinforced, epoxy composite automotive drive shaft. Mater Design 2010; 31(1): 514-521.

12. Valenza A, Fiore V and Di Bella G. Effect of UD carbon on the specific mechanical properties of glass mat composites for marine applications. J Compos Mater 2010; 44(11): 1351-1364. 
13. Sayer M, Bektaş NB and Sayman O. An experimental investigation on the impact behavior of hybrid composite plates. Compos Struct 2010; 92(5): 1256-1262.

14. Fiore V, Di Bella G and Valenza A. Glass-basalt/epoxy hybrid composites for marine applications. Mater Design 2011; 32(4): 2091-2099.

15. Amico SC, Angrizani CC and Drummond ML. Influence of the stacking sequence on the mechanical properties of glass/sisal hybrid composites. J Reinf Plast Compos 2010; 29(2): 179-189.

16. Venkata Reddy G, Venkata Naidu S and Shobha Rani T. Kapok/glass polyester hybrid composites: tensile and hardness properties. J Reinf Plast Compos 2008; 27(16-17): 1775-1787.

17. Khanam PN, Khalil HPSA, Jawaid M, Reddy GR, Narayana CS and Naidu SV. Sisal/carbon fibre reinforced hybrid composites: tensile, flexural and chemical resistance properties. J Polym Environ 2010; 18(4): 727-733.

18. Pourcheron L. A flax mini transat. ViaMare BySea 2011; 11: 7-11.
19. ASTM D 790-03. Standard test methods for flexural properties of unreinforced and reinforced plastics and electrical insulating materials. West Conshohocken, PA: ASTM International, 2003, pp.1-11.

20. ASTM D 3039/D 3039M-00. Standard test methods for tensile properties of polymer matrix composite materials. West Conshohocken, PA: ASTM International, 2006, pp.1-13.

21. ASTM D 5035-95. Standard test method for breaking force and elongation of textile fabrics (strip method). West Conshohocken, PA: ASTM International, 2003, pp.1-8.

22. Agarwal BD and Broutman LJ. Analysis and performance of fiber composites, 2nd edn. New York: John Wiley \& Sons, 1990.

23. Lee $\mathrm{H}$ and Neville K. Handbook of epoxy resins. New York: McGraw-Hill, 1967.

24. Lamy B and Pomel C. Influence of fiber defects on the stiffness properties of flax fibers-epoxy composite materials. J Mater Sci Lett 2002; 21(15): 1211-1213. 